\section{Journal of Engineering Sciences}

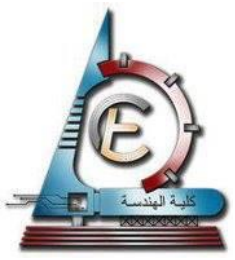

Assiut University

Faculty of Engineering

Vol. 47

No. 6

November 2019

PP. 853-867

\title{
AN APPROACH TO DETERMINE THE ENVIRONMENTAL IMPACT OF UNPLANNED HOUSING GROWTH PROBLEMS IN EGYPT CASE STUDY (AL-TALBIYEH DISTRICT-GIZA GOVERNORATE)
}

\section{Walaa Hussien Hussien}

Architecture Department - Pyramids Higher institute for Engineering and Technology.

Received 26 June 2019; Accepted 2 July 2019

\begin{abstract}
The current balance of unplanned residential areas in Egypt represents a problem of interrelated contemporary problems that have developed over a long period, during which their roots have been rooted in social, economic and political trends. Egypt has witnessed a population increase since the 1960s, accompanied by social and economic changes that have led to continued increase in rural-urban migration rates. The State has intervened in stabilizing rents and the low-income segment has given insufficient attention to the establishment of so-called low-cost housing, especially after the 1970s.

The private sector's reluctance to build up this category has resulted in the growing phenomenon of unplanned housing spread, which had, accompanied by many problems that threaten the existing environment and represent a deterioration that is reflected in the residents of these areas and extends its influence in the urban environment of its urban space.[7] Therefore, this paper aims to address the imbalances resulting from neglecting and exceeding the environmental values in the unplanned and growing residential areas in Egypt and the impact on its residents.

The study examines the phenomenon of increased violence and the spread of crimes among citizens in one of the unplanned areas of housing as an example - Al-Talbiyeh District-Giza Governorate in order to limit the shortcomings of environmental design and the impact to residents of this area in order to report the problem. The research found that the increase in violence in these areas is due to the decline of design and environmental planning.
\end{abstract}

Keywords: Environmental design - Unplanned housing - Violence

\section{Introduction}

Unplanned residential areas are neglected parts of cities that lack basic planning, environmental requirements and services for a decent life. These residential areas range from high-density areas, concentrated in the heart of old cities or on the periphery to agricultural lands or desert areas. These unplanned settlements are located under adverse social, economic and environmental conditions and without recognition or legal guarantees. The past five decades, causing one of the most important challenges facing development efforts in Egypt.[8]

The basic problems facing the design process are the relationship between human behavior and the surrounding environment. Their impact on each other and how to provide 
written data in the form of recommendations, allowing the designer to work in an atmosphere of understanding and full awareness, to produce a work that has a positive and comfortable effect. Psychologists have traditionally studied human behavior by analyzing personality traits such as intelligence, level of thinking, feelings, and tendencies. This is followed by a study of individual growth without taking into account the external influences surrounding it; about the behavior of Response, growth and abilities, and psychologists said that the surrounding environment factor influencing human behavior.

The previous studies in this field have dealt with these problems in terms of studying the following aspects:

- Analytical studies of random housing patterns.

- Technology in construction to upgrade slums.

- $\quad$ Management of urban development projects for slums.

- Slum problems on the one hand schematic standards.

Which did not study the environmental dimension and its psychological impact on the residents of the unplanned housing?

So, the study aims at determining the environmental problems in these unplanned residential areas. in order to balance the needs of the inhabitants of these areas on the one hand and to preserve the natural resources and invest the elements of the environment in order to meet the functional and cognitive sensory requirements on the other hand. Which positively affects the psychological aspects of the inhabitants of these areas, in which the prevalence of behavioral phenomena rejected as violence?

\subsection{Research problem}

The research problem is the spread of violence and crime in unplanned residential areas as a result of some environmental problems arising from faulty design standards and the omission of environmental considerations.

\subsection{Research hypothesis}

The spread of violence and crime in unplanned residential areas is due to the failure to observe the environmental design criteria and requirements of housing elements and urban spaces in those areas.

\subsection{Research objective}

The main objective of this research is to investigate the impact of the deterioration of the unplanned residential environment of buildings, streets, courtyards, services, social situation, etc. On the behavior and nature of its members and the nature of life in this residential area.

Explain the relationship of the deterioration of this type of housing, which lacks the standards and requirements of environmental design to the emergence of violence and the spread of crimes among its population.

\subsection{Research Methodology}

The research in this study follows the descriptive and analytical methods, through previous studies in environmental design and its impact on architecture in general and its impact of users in Unplanned Housing. 
In addition to the field study consists of studying, documenting and analyzing the current situation in the case study area, to reach from approach to determine the environmental impact of unplanned housing in general in Egypt.

\section{Approach}

The phenomenon of the growth of the unplanned residential area is a global phenomenon characterized by the majority of the countries of the world. Housing is one of the biggest problems in modern times.[7]. It is an urban problem, but it cannot separate from the social, economic, cultural and political conditions of a society. Rapid population growth in cities, with inadequate housing for lowincome people, has resulted in a severe population congestion in urban neighborhoods and in urban areas, as well as extreme areas outside them, which suffer from high population density and overcrowding, making it difficult to control On individual behavior, which increases the degree of underdevelopment and the unity of problems due to the deterioration of the elements of the environment.[3] Since the building is the physical framework that includes the activities and the social relations and therefore there is a controversial relationship between man and the environment built and the mutual effect between them; It can be a tool for the development of society, and it can also be a reflection of the values of society. The architectural characteristics of the place contribute to the definition of human actions and behavior, and human behavior and culture affect the architectural characteristics of the place, and this interaction between man and the environment built by environmental elements. From this point of view, it became necessary to look for the effect of the environment on these unplanned residential areas on humans. To how they affect their behavior.

From this point of view, it became necessary to look for the effect of the environment on these unplanned residential areas on humans. To how they affect their behavior. The importance of this research, which deals with part of the interrelationships between man and Architecture, is the effect of unplanned residential areas on the behavior of individuals. In an attempt to explain these effects and how the environmental impact can decide these problems.

\section{Residential growth}

Housing is a key component in the formation of housing groups. This gathering is based on social cohesion policy, housing around spaces with social activities that integrate and interconnect with each other, and the familiarity and interdependence of the population. Residential growth in cities:

- Residential development planned according to architectural principles:-

It is a residential development based on the building rules and laws of the state. This is the result of the emergence of suburbs with clear houses overlooking the streets of the organization, and services are available whether under construction services or social services such as education, treatment, security and others, as in the case of most countries. For example, Masdar City in Abu Dhabi, the mid-city of Cairo, London and others

- Residential development Not planned according to architectural principles:-

This is an informal response to the growing need for housing and shelter at the expense of surrounding land. This informal growth is one of the main causes of urban problems. Large suburbs and large population groups have emerged from these poor and deteriorating housing, which are called different names according to their location. [1].

Unplanned housing can be define as an urban phenomenon for communities that at some time have evolved into different circumstances without integrated urban planning and 
planning criteria. They were created by self-effort either by constructing buildings of only one or more or more nested houses, because it's done in the absence of law, usually for lowincome or low-income people, the result of the increase in population is due to the lack of housing that corresponds to the economic capacity of this category. Their buildings are constructed with simple local materials such as sheets, cardboard and clay. They may be upgraded to brick according to the economic status of their inhabitants.[6]. They built with the self-effort of their inhabitants. They are located in cities near or near the large neighborhoods - where they are a source of employment for their inhabitants - in an organized and organized amnesty, in which services are low or absent, whether social services (schools, hospitals, waste, etc.) Or infrastructure services, Electricity, sewage, etc.). Which causes many physical, health, security, and social problems, and this is evident in the overall shape of the region. These buildings are not environmentally safe due to their lack of public services and facilities. The area is not required to have a certain area. The area ranges from a group of small buildings to a whole group of neighborhoods, which vary in size and space spontaneously and are not subject to the planning laws. The boundaries between the individual and the surrounding social circles are almost non-existent in those areas. It also helps to create an abnormal personality of the human being and almost inhumane. The accumulation of one family with its different generations within one narrow space leads to psychological and social tension and leads to loss of the sense of privacy.[5]

\section{Housing patterns of unplanned areas}

Housing patterns of unplanned areas are classified by location, type of construction used and services, and the most prominent types of housing of these areas are:

- The pattern of housing of the public neighborhoods:

- It includes a large segment of residential areas with high population densities. In fact, the urban deterioration of these areas is not limited to housing, but extends to the infrastructure and public services networks.

- The pattern of nest accommodation:

- A different type of housing and is at the lowest levels of housing, the nest houses or huts of wood or laminate in the form of clusters of adjacent nest, and the inhabitants of these neighborhoods low standard of living.

- Pattern of Cemeteries and Bungalows:

- Cairo is characterized by the phenomenon of cemeteries inhabited by a large proportion of the population with low incomes.

- The style of rural accommodation in urban areas. [2]

\section{The relationship between human behavior and the built environment}

The psychological and psychological sciences of mankind evolved at the end of the last century, and many scientists concluded that there is great importance to the study of the environment entirely and its impact on the behavior of the individual, a shift from the traditional psychology that was centered around individual behavior to a comprehensive view of the study of the behavioral context: Is the framework that includes all transactions between individuals and social and physical components of the surrounding environment as Stokolis saw in 1981.) In this context, the concept based on the study of behavioral psychology has changed and there is an important relationship between man and the place in which he is present. Hence, two new approaches emerged:

-Ecological psychology.

- Environmental psychology.[4] 
The integration between the two new psychologies has led to the emergence of studies on the relationship of the environment to human behavior, both of which deal with the study of this relationship in a special and different way

- Ecological psychology and the relationship of human behavior to the environment

The relationship between living organisms and all the components of the environment in which they live can be defined. There is an interrelated relationship between living organisms and the environment. Therefore, a set of basic ideas has developed that explain the relationship between the environment and human behavior:

- All living things are interconnected.

- There are internal forces of the human and external, which is in the surrounding environment affecting his behavior.

- All organisms have a natural inclination to adapt to the environment in which they exist to reach harmony and harmony.

The behavior of man in his responses to the continuation of his life, and to face the fluctuations and changes of the environment, and therefore the ecological concepts - in psychology - proved that the environment affects the behavior is conceived as a dynamic system. A combination of physical and social components. Where individuals are present and behavior is the process of coping with these conditions. [3]

- Lewin's theory of the relationship between the environment and human behavior

Lewin explained the relationship between the environment and human behavior through three basic elements: behavior, individuals and the environment, where he equated the importance of both individuals and the environment. As a result of their complementarity, behavior (behavior $=$ environment + individuals).

- Barker's theory of behavior

Barker reached conclusions about the importance of the context in which the behavior is taking place, and this is the basis of his theory of behavior. In this context, Barker reached a number of important characteristics of the behavioral field:

- Behavioral domain a group of events and interactions occurring within a specific spatial and temporal framework.

- The behavioral field consists of individuals, tools, elements, and elements that represent spatial boundaries (walls, columns...), and a certain pattern of behavior related to the function of the place. Individuals in the behavioral field do not mean the presence of specific individuals, but the presence of an appropriate number of individuals, to exercise activity, in addition to the elements of the field to create the appropriate conditions.

- There are consistency and consistency between the parts and components of the behavioral field of elements, individuals, program activities, and behavior to achieve the behavioral field alone.

It is noted that the built environment, represented by its elements and a spatial framework, has a fundamental role with the time factor and the activity program in the formation of a coherent structure that guides human behavior. 
- Bronfenbrenner's theory of the effect of the environment on the growth of human behavior

Bronfenbrenner defined the environment that influences human behavior as a nested combination of a range of environments, each containing the other - including attitudes such as the classroom or housing. Interactions and interactions between these environments represent the forces that influence human behavior in a particular situation. Alternatives to a model has developed in this environment:

- Micro System: A system for the position that surrounds the person directly.

- Meso System: A system of relationships that links the former regime to the set of external systems that affect human behavior.

- Exosy System: The system of the external environment surrounding the situation in which the human is located.

- Macro System: which is the system of the general framework and cultural context of the situation in which human beings exist. [4]

In conclusion, the three theories emphasize the effective influence of the environment surrounding man on his behavior, and recognize the importance of the physical dimension as a component of this environment.

- Environmental psychology and the relationship of human behavior to the built environment:

Studies have developed a new dimension that is the relationship between the built environment and human behavior, and showed the positive role of the behavior of individuals in the creation of patterns of a different built environment.

As a result, scientists have concluded that the behavior of individuals in the built environment affects the characteristics of that environment; the built environment is not limited to being a factor affecting the individual but a social and cultural product for these individuals.

In 1977, Canter introduced a tripartite model of the place, which includes physical characteristics, behavior, and activity of individuals, perceptions and concepts of individuals about activities in this place. It was agreed that the designer should not only be interested in measuring and understanding the behavior, requirements and needs of individuals in the built environment, but knowledge of the information that clarifies The validity of its circulation.[4]

- Behavior as one of the psychological processes associated with human interaction with the environment

Human behavior is characterized by the psychological relationship between man and surrounding environment. This is equally important in understanding the nature of human behavior, and a series of studies have focused on human behavior. Which has direct access to the architectural design field in particular, and human emotions focus on a specific set of desires - according to all the studies and research done in this area - ranging from need to a sense of security to a sense of belonging to a certain cultural or literary level, and these desires are also arranged by age, society and environment, and these wishes are expressed as follows:

- Vital living necessities (food, drink, excretion....)

- The need for security and safety (stability, privacy...)

- Social needs (belonging, participation...) 
- To satisfy self-confidence and self-realization.[3]

Human deal with the built environment through a number of psychological processes, each with its different characteristics, they are also integrated into a sequential model that represents the individual's with the surrounding environment. Fig1
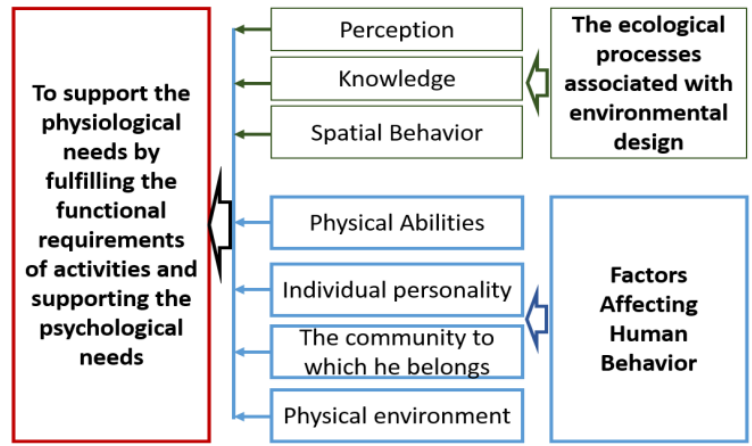

Fig. 1. Relationship between psychological processes and factors affecting human behavior. (By: researcher)

$\checkmark$ From the foregoing, it turns out:

- Man's behavior in the built environment is called his urban path, he is the result of genetic or personality traits or social and religious influences, and of civilization and urban policy, the environment combined with genetics and personality, plays a key role in determining what this behavior is.

- Human requirements in the residential environment may divide into two categories:

- Physiological requirements of vital living need.

- Psychological requirements of social needs, both individual and group, encompassing those related and interrelated human needs (privacy communicating and building social relationships - feeling safe - feeling belonging - realizing oneself and the right to expression and participation)

- The shape and architecture of the building affect the character of the inhabitants, and there is interaction between physical framework and the human being, and human influence is often shared with the physical environment in which it lives, so most therapists to solve city problems have been architectural therapists.

\section{$\checkmark$ Models of human behavior in the built environment}

You can divide human behavior in the built environment into three basic models to study and interpret behavior within the built environment; It is through relationships that the individual is exposed to in relation to the environment, and that the rest of the classifications relates to the personality of the individual and are divided into:

- Individual behavior model: individual behavior, output of personality and environmental factors.

- The behavior between two person model: the behavior of the individual in social relations is not only irrelevant to the individual, but is also determined by the personal and environmental influences of the other individual's behavior.

- A model of community behavior: each member of the group reacts to the other members of the group to define the individual behavior of the group, He is reacting to her behavior demands until he realizes the benefits for himself, so that the 
individual is bound to her and takes her behavior as a model for his behavior and it represents that clearly in following and applying customs and traditions · [3]

For a person, the built environment is like a snail, it shapes its body inside it according to its shape, and it is this form which the animals separate in the sense that the physical environment can influence the human and contribute to its variation as it has its shape in accordance with its needs and its behavior "Hassan Fathy " There is a reciprocal impact of the built environment and human behavior. The environment of streets, buildings and open Spaces is a part of the surrounding environment; and it comes to the requirements of man and society met and reflect his ideas, culture, beliefs, and values. They in turn influence his actions and reactions. The surrounding environment generates the reactions and behaviors of the Constantine.

\section{The effect of unplanned housing environment on human behavior}

The effect of unplanned housing environment on human behavior has an impact on individuals psychologically, physically, socially, etc., As it affects the area in which it is found, this effect even extends to the city as a whole it causes visual contamination and distorts the urban landscape. - Most of these areas are rife with diseases, social problems, conflicts and high rates of family disintegration, delinquency, crime and legal malfeasance. In addition to the high congestion rates, the presence of high densities and the metal effects of behavior effects, there are high levels of ignorance; disease and insecurity are also high in most of those areas, as a result of inadequate public services and the infrastructure of education, health, security services, electricity and other services. Provides electricity and other services. Some family members or the surroundings are in a state of frustration and depression, resulting in violence because the dehumanizing physical environment leads to poor psychological conditions in the population and, consequently, the spread of societal ills [4].

\section{Case Study (Al-Talbiyeh District - Giza Governorate)}

\subsection{Approach about region}

Is an area in the governorate of Giza, the old separation zone between Giza and the Pyramids, and currently administratively administers the urban section (Giza). And reach the area of Kafrthermus of the Department of Bulaq Dakrur, a famous station in the regions of Faisal and Haram and contains a high density of population and is a mediumlevel area, which fall according to the areas not planned (Figure 2)
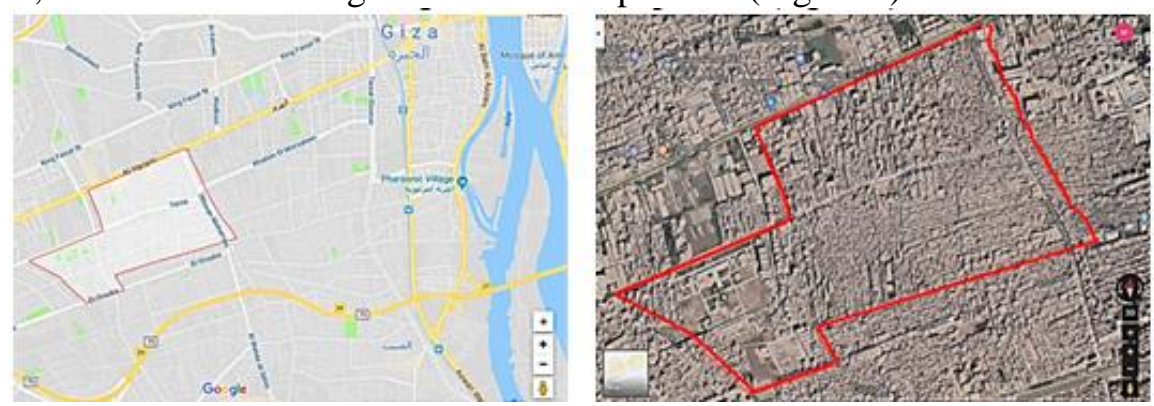

Fig. 2. Map of Al-Talbiyeh District - Giza Governorate (Google map 10-6-2019).

\subsection{Some phenomena of violence in the region}

There are many aspects of violence in the region, which occur at close intervals here are some examples, Figure (3) 

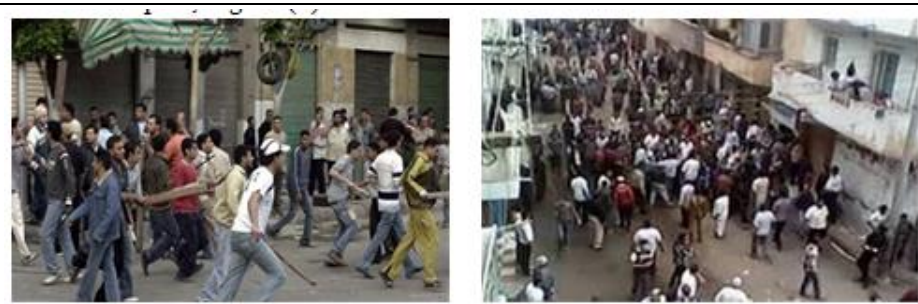

Fig. 3. Quarrels and violence between the inhabitants of the District.(https://m.elwatannews.com 5-6-2019)

- One person killed and another injured in Scrimmage Because of family problems, Talabiyh Tuesday, 28 August 2018

- A young man committed suicide because of a psychological crisis Talabiyah Thursday, July 19, 2018

- The body of a lady was found cut in on Talbiyah Friday, 26 April 2019

- A girl was tortured by her mother in Talbiyah Tuesday, 18 December 2018

- A young man killed his brother for trying to hit their mother in Talbiyah Thursday, 05 April 2018

- Student worker hanged himself hanging rope on the roof of his room because of his bad mental Saturday, 31 March 2018

- Student killed a person with a knife because of problems in Talbiyah Sunday, March 25, 2018

- Unemployed trading in firearms and ammunition on Talbiyah Friday, May 31, 2019

- A student was killed due to previous problems in Talbiyah Saturday, March 24, 2018

- Kidnapped child and ransom demanded 1.5 million pounds in Talbiyah Monday, 28 May 2018

- The owner of a workshop set fire to the owner of a company because problem on Talbiyah Tuesday, 19 December 2017

\section{Deficiencies in the standards and requirements of design in the case study district}

\subsection{First: Urban planning (District)}

The site map shows that the random pattern, not harmonious and have not free zone of anywhere acting as an outlet for the area fig. (4)

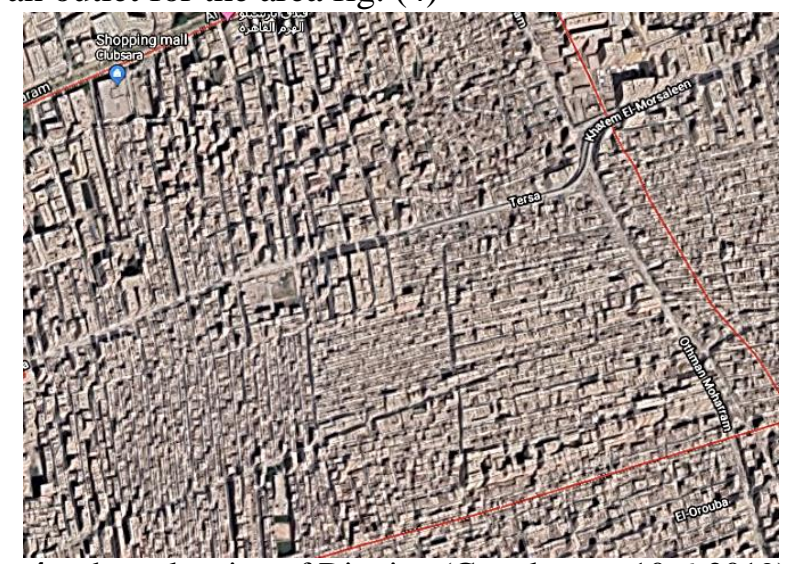

Fig. 4. urban planning of District (Google map 10-6-2019).

$\checkmark$ Analysis of the urban planning of District as shown in the figure is:

- There is no clear urban planning for the area

- High building density of the District and bad condition of the building 
- There is no space that can be exploited as an air breather

- Interference of some uses with residential areas such as overlap of commercial and industrial activities and crafts with accommodation

- No green areas

- High population density and lack of existing services

- Poor infrastructure networks and poor drainage systems in homes and main roads

- Weakness of road lighting networks

- Bad roads

- The narrowness, lack of clarity and regularity of the streets, where irregularity prevails, and unorganized planning of construction. This is due to the lack of a structure of urban planning before the construction of these areas, and therefore overlap houses in those areas randomly. Fig. (5)
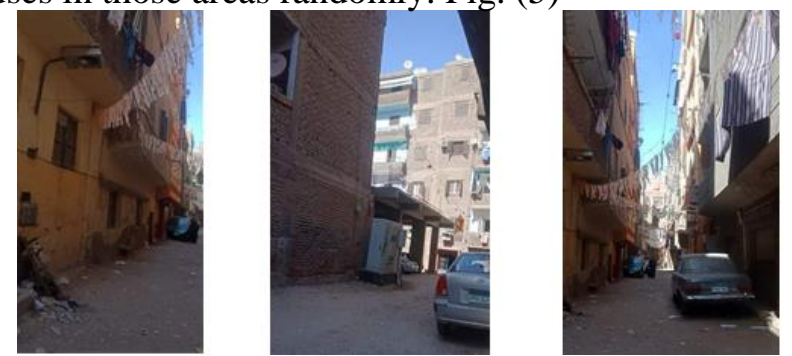

Fig. 5. the narrowness of the streets and irregularity and bad condition of buildings. (By: researcher, 16-6-2019)

- Overcrowding and overlap between housing, leading to loss of privacy.

- Small areas of gardens and parks may be absent in many of them.

- The deterioration of public services, which may result in their lack of infrastructure, and the overloading of infrastructure; it is characterized by sewage spills, electricity cuts and waste accumulation with few public service buildings such as hospitals, educational buildings and others. Fig (6)
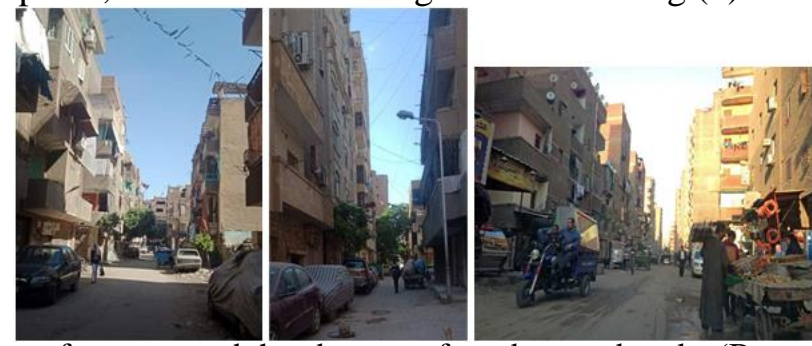

Fig. 6. Small areas of squares and the absence of gardens and parks.(By: researcher, 16-6-2019)

- Congestion and traffic jams, lack of parking spaces, difficulty in moving by car, increasing the number of trucks and the difficulty of entering ambulances to the District

- The urban planning of the District is unable to accommodate the movement of cars and various transport and lack of basic services from stations or parking areas. Fig. (7)

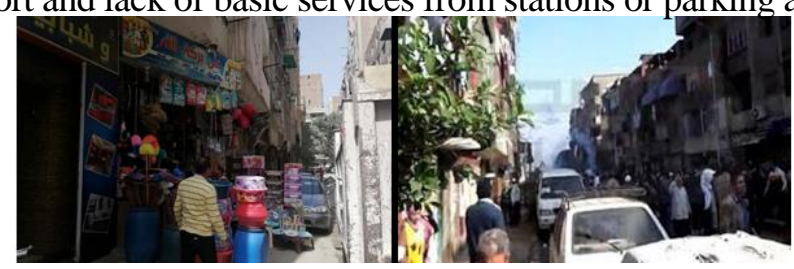


Fig. 7. narrow streets and the difficulty of traffic and the overlap of uses.(By: researcher, 16-6-2019)

\subsection{Second: architectural design (building - residential unit)}

Analysis of the state of buildings in District as in the Fig. Shown

- Poor in design and low quality of buildings; the houses are built of simple materials available and the population is not interested in their maintenance

- Lack of openings (windows)

- The use of corridors, streets and roads between the units to carry out various activities to compensate for the lack of space units

- The workplace is close to housing and may be inside or attached to the residential unit

- The problems of housing environment such as the destruction of walls and moisture and rotting walls Fig. (8)
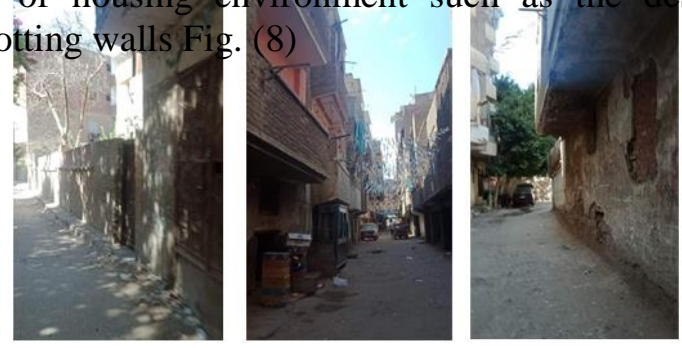

Fig. 8. Buildings deterioration and low quality.(By: researcher, 16-6-2019)

- Narrow spaces and lack of lighting, so that most of the species do not enter the sunlight

- There is no maintenance of housing

- The residential area is poor shelter from inside and outside the city

- Environment is not clean and the spread of insects and Stray animals, epidemics and sewage problems

- Accumulation of waste near housing units

- The piles of garbage, which are often burned, and the solid waste, and lack of health services and playgrounds, accumulate diseases

- Dangerous structural threatens the security and safety of its inhabitants Fig. (9)
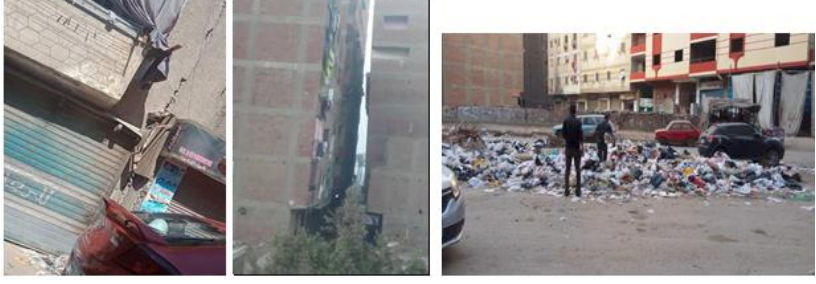

Fig. 9. Garbage accumulation and structural deterioration.(By: researcher, 16-6-2019)

- The existence of craft activities such as workshops, foundries, paint and repair of cars, marble, plastic materials, tanneries, slaughterhouses, etc.

- Buildings do not observe the engineering standards in terms of safety and breadth, air and sun outlets, and provide suitable places for cooking area and toilets.

$\checkmark$ For residential unit design

- The space is not enough for the number of occupants and the number of floors of 3: 12 floors 
- The average residential unit area is 60 square meters

- Unit haven't reception and guests set in the living space, which is often in a mid of the unit

- - Shortage of bedrooms, number in most units

- - Often there is no dining room

- - Living shares the reception, food and sometimes sleep.

- - There is a kitchen and one bathroom in small and narrow areas and not qualified

- - Put kitchen appliances in bed or living room

- Problems resulting from a shortage in environmental design in the case study district

First: From the environment.

- Reduce its chances of improving air quality and reducing pollution

- Pollution resulting from the overcrowding of these gatherings, workshops and the resulting waste

- High population density and increasing rates of overcrowding. Leading to the spread of epidemics and diseases

- The general decline in the state of health, education, security and others.

- These areas are devoid of aesthetics and green spaces, due to the emphasis on building the largest number of houses for accommodation, thus becoming a deteriorating environment in terms of its general appearance, infrastructure and dangerous structure.

- The negative perception of the inadequacy of the neighborhood and the old housing of the high life and the better social level

- The small distances between the windows that led to the low degree of privacy, and the sense of social discrimination as well as being ready for incidents and security problems and low level of social and recreational services

- The low level of awareness of the population of these areas, which affects the lack of cleanliness of the lack of the population of these areas to clean water most of the time in addition to non-human ways to get rid of waste.

- Disturbance and noise as a result of the presence of workshops and a lot of tok-tok as transportation in the area

- Air pollution and the presence of smoke and heavy exhausts in addition to the presence of a pharmaceutical company that causes radioactive contamination of the area

- Deterioration of public services such as Cleanliness, environmental health, pesticide spraying, afforestation, fresh water supply and sanitation, storm water drainage, electricity, telephone and stray animals, as well as service facilities such as schools, hospitals,

- The continuous decline of the urban environment surrounding the urban features, as well as the deterioration of the infrastructure network with the growing growth of the population with low standard of living, as well as the accumulation of landfills and lack of attention to the clean area

- Increase the percentage of environmental pollution in various forms of:

- Noise pollution: arising from the presence of noise from the trades and workshops in these areas, as well as vendors and tok-tok

- Visual pollution: resulting from the lack of harmony in heights and colors of destinations and the spread of garbage and sewage surge

- Air pollution: due to poor ventilation and lack of access to the buildings and residential apartments due to the lack of streets or poor architectural design in addition to the lack 
of green spaces and open spaces as well as the absence of a mechanism to collect waste, which led to the accumulation and poor Cleanliness and the spread of epidemics.

Second: Psychologically and Behaviorally

- Poverty at the family level

- Increasing the isolation and heterogeneity of the population; these areas include populations of different regions and cultures and conflicting ideas and cultures.

- The weakness of the rule of law, the emergence of group authority and the emergence of solidarity groups from within the region that threaten the security and safety of urban areas

- Weak security conditions as a result of social isolation due to the cultural closure of the population of these areas

- A large percentage of the population of these areas is classified as low income, and the proportion of unemployed to the labor force in these areas is highest, and the percentage of people with economic activity among individuals to about one third of the population Unemployment is a key feature of the population of these areas due to the low or no education level, So poverty and illiteracy in many cases lead them to do whatever is criminal and fall under that Drug dealing, Trade human organs, and theft.

- The residential area suffers from marginalization and suffers from poverty, physical and moral deprivation, and deterioration of the living and other conditions.

- Usually inhabited by poor, unskilled and uneducated workers who do not own houses

- Clustering at home and restricting free individuals

- Some misconducts according to design such as joint sleep between the adult children, or sleep joint with the fathers

- Violation of privacy between neighbors and members of one family

- Early marriage and leaving education

A racist view of the region and its population causes problems (social, economic and...)

$\checkmark$ From the foregoing, it turns out

Residents of this area are exposed to environmental conditions and low life due to lack of the environmental dimension in the area design and planning, which reflected in turn on their behavior, causing the spread of violence phenomena among residents of the region as one of the results of the decline design and environmental planning

\section{Results}

- Housing is a response to the most important humanitarian needs, and unplanned housing is a form of residential growth in cities, takes different styles vary by place and building materials.

- Unplanned areas of residence are either random or other areas that have become random over time due to an increase in population beyond services, or because they are located at a terminal location and away from transportation, or have not met the requirements of general planning and so forth.

- The decision on the unplanned place is not related to street planning and arrangement only (planning of buildings and streets) but includes other aspects such as the extent of deterioration of buildings and the adequacy of the land and the amount of population densities and rates of overcrowding and availability and deterioration of public services and the economic situation of the population and land ownership and others. 
- Most unplanned areas are characterized by general underdevelopment and degradation, and features of underdevelopment in the physical, social, economic and environmental aspects of the residential area.

- The basic human needs are a major influence on human behavior; the form and nature of human behavior come as a response to these needs and forms the basis of their behaviors and lifestyle in the vacuum environment in which they exist.

- Human behavior and reactions are the result of the interaction of the personality with the environment, which is either to be a behavior of nature or acquired and takes two forms of relationships either individually or collectively.

- The environment surrounding the human being with all its natural, physical and social components is one of the most important factors that have a direct impact on the human being, which is based on its personality, behavior, reactions and lifestyle.

- There is a reciprocal relationship between the urban and human environment, where they affect each other.

- The urban environment with all its components of buildings, streets and open spaces come to meet the requirements of man and society and reflect the ideas and beliefs and values.

- It is difficult to change the basic direction of human behavior resulting from its principles and values, in contrast to the behavior resulting from its surrounding environment, whether it is a physical or social environment.

\section{REFERENCES}

1. The Challenge of Slums, Global report on Human Settlement 2003, United Nations Human settlement program, (UN HABITAT), Earthscan Publications Ltd, London and Sterling, VA.

2. Berner, E. (2001) Learning from Informal Markets: Innovative Approaches to Land and Housing Provision. Development in Practice 14, 1

3. Canter, D. The psychology of place, New York, ST, martins

4. -Barker، R.G.: Ecological Psychology: concept \& Methocls studying the environment of human bbehavior, Stanford, GA.

5. United Nations Human Settlements Program (UN HABITAT), Global Indicators Database 2014.

6. www.worldmapper.org, Copyright 2006 SASI Group (University of Sheffield) and Mark Newman (University of Michigan).

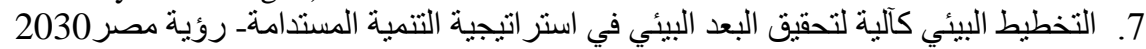

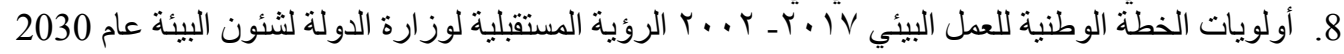

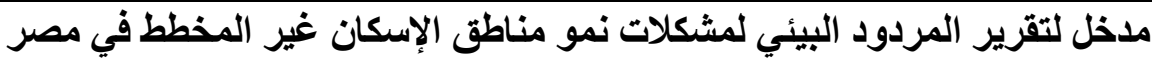

دراسة حاله (منطقه الطالبية_محافظه الجيزة)

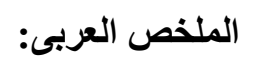

يمثل الرصبد الحالي من المناطق السكنية غير المخططة في مصر مشكلة من المشكلات المعاصرة المنداخلة

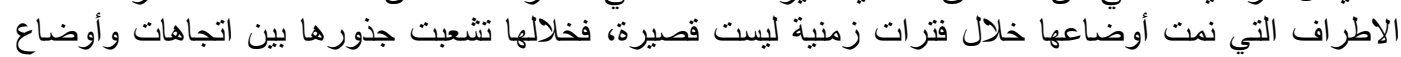

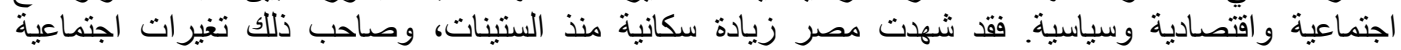

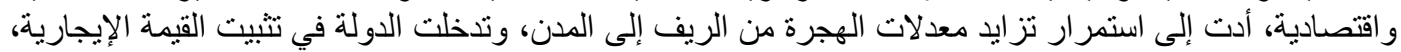

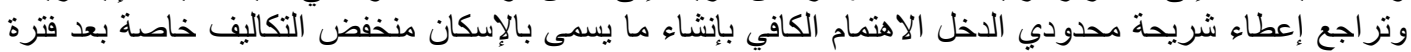

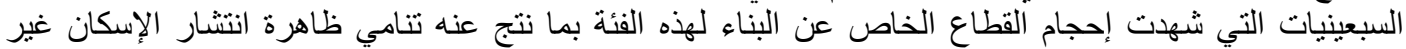

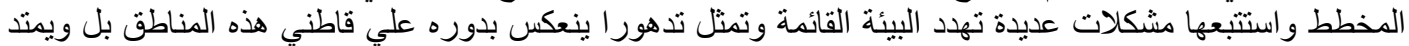

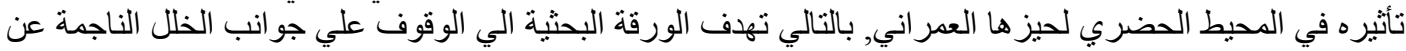

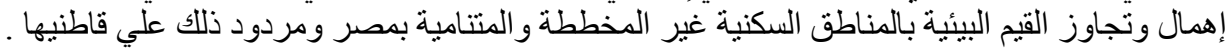


Walaa Hussien Hussien, An approach to determine the environmental impact of ................

ويتتاول البحث بالدارسة حصر لظاهره تز ايد العنف و انتشار الجرائم بين المواطنين بأحد مناطق الإسكان غير المخطط كمثال -

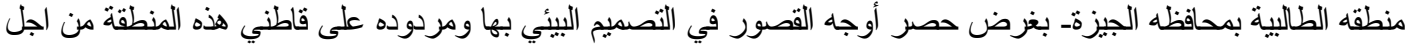
تقرير المشكلة بها. وقد خلص البحث الي ان تز ايد معدلات العنف بتلك المناطق برجع الي تراجع التصميم و التخطيط البيئي بها. 